\title{
Tratamiento de un caso de pedofilia desde la terapia de aceptación y compromiso (ACT)
}

\author{
Treatment of a Paedophilia Case Using ficceptance \\ and Commitment Therapy \\ Tratamento de um caso de pedofilia desde a terapia \\ de aceitação e compromisso [ACT]
}

\author{
Rafael Jiménez Díaz* \\ *Asociación alternativa, Málaga, España.
}

Doi: http://dx.doi.org/10.12804/ap134.3.2016.07

\section{Resumen}

En este artículo se expone un caso clínico de pedofilia en el que la conducta (masturbación con cierto contenido mental) tenía consecuencias tanto positivas como negativas para el cliente. Debido a este conflicto, cuando el cliente experimentaba deseos pedófilos, intentaba controlarlos o evitarlos, empeorando paradójicamente el problema debido a las consecuencias negativas adicionales que el acto de control llevaba consigo, como mostrará el análisis funcional. Como tratamiento se aplicó la terapia de aceptación y compromiso (ACT) con el objetivo de que el cliente saliera del círculo vicioso de lucha y rendición respecto a la conducta pedófila mediante la aceptación de sus eventos privados, ya que esta aceptación está al servicio de acciones valiosas. Por último, se propone que la ACT muestra potencial en el tratamiento de este tipo de problemas, ya que, en el caso tratado, produce una disminución del sufrimiento subjetivo experimentado por el cliente y la realización de conductas encaminadas a sus propios valores personales.
Palabras clave: evitación experiencial; pedofilia; paradoja; tensión; análisis funcional; análisis topográfico; aceptación; compromiso.

\section{Abstract}

In this article we present a clinical case of paedophilia in which behavior (masturbation accompanied by certain mental content) had both positive and negative consequences for the client. Due to this conflict, when experiencing paedophile urges, the client attempted to control or avoid them, paradoxically making the problem worse, due to the additional negative consequences linked to the control efforts,as will be revealed through the functional analysis. Acceptance and Commitment Therapy (ACT) was used in order to break the vicious circle of struggle and rendition in relation to the paedophile behaviour, through the acceptance of private events, as acceptance serves other important actions. Finally, it is proposed that ACT shows potential for the treatment of this type of problems, as in this case it helped decrease subjec-

* Asociación alternativa, Málaga, España.

La correspondencia relacionada con este artículo debe ser enviada a Rafael Jiménez Díaz, C/ Jaén \# 16, Vélez-Málaga (Málaga), C.P.: 29700. Correo electrónico: rfjdpsicologo@hotmail.com 
tive suffering in the client and facilitated behaviours consistent with his own personal values.

Keywords: avoidance; paedophilia; paradox; tension; functional analysis; topographic analysis; acceptance; commitment.

\section{Resumo}

Neste artigo se expõe um caso clínico de pedofilia no que a conduta (masturbação com certo conteúdo mental) tinha consequências tanto positivas quanto negativas para o cliente. Devido a este conflito, quando o cliente experimentava desejos pedófilos, tentava controla-los e/ou evita-los, piorando paradoxalmente o problema devido às consequências negativas adicionais que $\mathrm{o}$ ato de controlo levava consigo, como mostrará a Análise Funcional. Como tratamento aplicou-se a Terapia de Aceitação e Compromisso (ACT) com o objetivo de que o cliente saísse do círculo vicioso de luta e rendição respeito à conduta pedófila mediante a aceitação de seus eventos privados, já que esta aceitação está ao serviço de ações valiosas. Por último, propõe-se que ACT mostra potencial no tratamento deste tipo de problemas, já que, no caso tratado, produz uma diminuição do sofrimento subjetivo experimentado pelo cliente e a realização de condutas encaminhadas aos seus próprios valores pessoais.

Palavras-chave: evitação experiencial; pedofilia; paradoxo; tensão; análise funcional; análise topográfica; aceitação; compromisso.

Si nos basamos en el DSM-IV-TR (APA, 2002), para que un paciente sea diagnosticado con pedofilia debe mostrar, durante un periodo de al menos seis meses, fantasías sexuales recurrentes y altamente excitantes e impulsos sexuales o comportamientos sexuales ligados a los niños. Además, estas fantasías, impulsos o comportamientos deben provocar un malestar clínicamente significativo o deterioro social, laboral o de otras áreas importantes de la actividad del individuo. Esta definición, en apariencia bastante coherente, no está exenta de controversias. En primer lugar, hay comportamientos que provocan malestar individual o social en una cultura pero no en otra. Así, en Occidente, el que una persona adulta mantenga relaciones sexuales con una persona menor de 18 años no sólo está mal visto, sino que incluso puede ser perseguido por la justicia. En cambio, en la cultura gitana, en muchos países musulmanes y en algunas regiones de México y Suramérica es normal que se casen chicas menores de edad con hombres adultos.

Además de estas diferencias de criterio, otro problema a la hora de diagnosticar una pedofilia radica en determinar los márgenes de las conductas implicadas en dicho trastorno. Según la definición anterior del DSM-IV-TR (APA, 2002), no sólo se consideran anormales las conductas sexuales explícitas, sino también los pensamientos o fantasías placenteras relacionadas con los estímulos parafílicos (en este caso, niños menores de edad) siempre y cuando se den de forma recurrente como mínimo a lo largo de seis meses. Esto añade aún más dificultad al tema, ya que ¿qué se considera recurrente?, ¿todos los días?, ¿una vez a la semana?, ¿un par de veces al mes? Además, que las fantasías o pensamientos parafílicos deban de ser considerados placenteros por el paciente no está nada claro. Muchos pacientes aquejados de parafilias (incluida la pedofilia) refieren pensamientos que son ambivalentes o contradictorios, es decir, no son placenteros o desagradables sin más. Así mismo, algunos de ellos mencionan experimentar tanto deseos de controlar o evitar sus fantasías sexuales parafílicas, como culpa o tensión psicológica acompañada de una activación fisiológica desagradable antes de rendirse ante tales fantasías o llevar realmente a cabo las conductas parafílicas, tras lo cual sí experimentan placer (Jiménez, 2012).

Con este panorama, tendría sentido emplear la ACT (Hayes, Stroshal, \& Wilson, 1999; Hayes, 2004; Wilson, \& Luciano, 2002), terapia que se ha mostrado eficaz a la hora de abordar problemas psicológicos en los que funcionalmente la evitación experiencial juega un factor determinante. El 
concepto de evitación experiencial en la ACT o trastorno de evitación experiencial (Hayes, Wilson, Gifford, Follette, \& Stroshal, 1996) hace referencia a una dimensión funcional del sufrimiento psicológico en la que un individuo se halla envuelto de forma crónica y persistente, a pesar de lo desadaptativo que esto le resulta para su vida. Básicamente, los esfuerzos de una persona por evitar ciertos pensamientos, sentimientos, sensaciones fisiológicas o eventos privados de cualquier tipo producen el efecto contrario. En síntesis, la ACT buscaría favorecer el contexto adecuado para que el paciente tome conciencia de los efectos paradójicos y perjudiciales de la evitación experiencial, ofreciéndole como alternativa la aceptación de los eventos privados, la cual estará al servicio de la actuación en función de valores personales.

\section{Descripción del caso clínico}

El cliente del caso clínico de pedofilia que se expone se trata de M., varón de 23 años, soltero y estudiante de tercer semestre de periodismo. M. solicitó ayuda para intentar controlar unos pensamientos obsesivos de índole sexual que venía padeciendo desde hacía unos cinco años.

El cliente informaba que desde la infancia fue una persona tímida e insegura, influenciado por progenitores que eran excesivamente sobreprotectores. Sus padres lo acompañaban al colegio hasta los 11 o 12 años, pese a que el centro escolar estaba ubicado a escasos metros del domicilio familiar. Además, hasta esa edad no le permitían salir solo a la calle. En esas circunstancias, M. creció con bastante timidez y pocas habilidades sociales. Le costaba mucho entablar amistades y por ello se sentía inseguro y con poca autoestima. El cliente refiere que al cumplir 12 o 13 años empezó a sentirse atraído por las chicas de su edad. Así, M. relata que se masturbaba pensando en ellas, pero nunca fue capaz de interaccionar socialmente con ninguna. Algunos compañeros de colegio ya habían empezado a salir con chicas y contaban sus primeros escarceos sexuales con ellas y, por ello, M. refiere que se sentía acomplejado e inferior con respecto a ellos. El cliente pensaba que jamás tendría novia ni estaría con ninguna chica debido a su timidez y temía que su única experiencia sexual fuera la masturbación.

Con el paso de los años, M. se sentía cada vez más inseguro y empezaba a estar deprimido. Es en torno a los 17 años cuando M., que seguía sin entablar relaciones con chicas, se da cuenta de que con niñas de 11 o 12 años no se siente tan tímido como con las compañeras de su edad. M. recuerda que, de repente, surgió en su cabeza la posibilidad de intentar "algo" con ellas, pero pronto rechazó esa idea, ya que las consideraba muy pequeñas para él. A pesar de haber descartado, de inicio, esa idea, el cliente menciona que se sintió culpable por haber barajado tal posibilidad. A partir de ese episodio, M. empezó a esforzarse por no tener pensamientos sexuales cuando se encontraba en situaciones en las que estuvieran presentes niñas más pequeñas que él.

De esta manera, cuando el cliente se encontraba con niñas de menos edad que él pensaba cosas como: "Tengo que intentar no pensar en que me atraen estas niñas". Tras estos pensamientos aparecían otros del tipo: "Voy a mirarlas para asegurarme de que no me gustan". Entonces, M. les lanzaba un fugaz vistazo, apareciendo a continuación los pensamientos "Estoy mirando a estas niñas, soy un degenerado" y "Aunque prefiero las chicas de mi edad, estas niñas tienen cierto atractivo". El cliente, entonces, se sentía más culpable aún al percibir que estas chicas, más pequeñas que él, "le atraían".

M. enseguida se preocupó ante la posibilidad de que, cuando se masturbara, entre sus fantasías sexuales pudieran aparecer imágenes de estas niñas más pequeñas que él. Pensaba: “Tengo que evitar pensar en niñas pequeñas", pero, paradójicamente, acababa pensando justo en ellas. El cliente menciona que, sin entender muy bien el motivo, estos pensamientos llegaban acompañados de cierta relajación placentera, hecho que lo angustiaba sobremanera. Además, notaba su propia erección 
bajo el influjo de estos pensamientos. El cliente experimentaba una especie de anticipación de placer al estar en contacto con esas imágenes. Entonces, M. intentaba asegurarse de que esos pensamientos no le resultaban placenteros, fantaseando brevemente con ellos para ver qué efecto le producían. Muy a su pesar, descubrió que dicha aproximación a los pensamientos que pretendía evitar le resultaba placentera. Como el resultado de su sondeo no era el que esperaba, sino que, efectivamente, había experimentado placer al fantasear con los pensamientos que pretendía reprimir, $\mathrm{M}$. se sentía cada vez más confuso y culpable.

M. refiere que experimentó esos episodios de intentos de control de los pensamientos y relajación placentera (cuando finalmente éstos aparecían) durante varias semanas consecutivas, hasta que un día optó voluntariamente por rendirse (al resultarle imposible evitar la aparición de tales pensamientos) y se masturbó fantaseando con chicas de menos edad. El cliente recuerda aquel episodio como un acto impulsivo y repentino, en el que se dejó llevar por la frustración acumulada al no poder hacer desaparecer de su mente los pensamientos relacionados con niñas menores que él. Según él, se rindió a la "tentación" para no seguir sufriendo. Después de ese hecho, M. se sintió terriblemente culpable, ya que si consideraba que pensar en niñas pequeñas estaba mal, acompañar estos pensamientos con la masturbación era aún peor.

A partir de ahí, mientras más se esforzaba por controlar los pensamientos relacionados con niñas pequeñas, más intensos eran y no desaparecían hasta que volvía a rendirse a ellos, integrándolos en una fantasía sexual mientras se masturbaba. Además, el cliente menciona que, aunque seguía sintiendo mayor atracción por las chicas de su edad que por las menores, paulatinamente las fantasías sexuales con menores fueron haciéndose predominantes. De esta forma, si M. iniciaba la masturbación fantaseando con chicas de su edad (o con actrices, modelos, etc.), inmediatamente era “invadido" por las fantasías pedófilas y, por mucho que se esforzase, no podía retomar las fantasías iniciales. Así mismo, una vez que ya había iniciado la masturbación fantaseando con chicas de su edad, el flujo de excitación sexual desencadenado por ellas hacía que después fuera más difícil reprimir las fantasías con las niñas pequeñas una vez que aparecían. Esto ocurría una y otra vez, sintiéndose el cliente cada vez más culpable y perdiendo la poca autoestima que le quedaba.

El cliente refiere que llegó a intuir que sus intentos de control estaban haciendo que cada vez se encontrara peor e intentó olvidarse del tema, quitándole importancia, diciéndose a sí mismo cosas como: "Sólo son fantasías, tampoco es tan grave" o "No le voy a dar tanta importancia a esto". Estas palabras de autoconsuelo lo aliviaban momentáneamente, pero inmediatamente pensaba que no podía olvidarse de algo tan preocupante y que era su deber controlar esos pensamientos y asegurarse de que verdaderamente no le atraían las niñas pequeñas $\mathrm{y}$, entonces, todo volvía a empezar.

M. recuerda que, paulatinamente, empezó a extender su preocupación a muchas otras situaciones. $\mathrm{Si}$, por ejemplo, en las noticias de televisión hablaban de casos de pornografía infantil o de abusos sexuales, se preocupaba por la posibilidad de que él llegara a convertirse en uno de esos delincuentes. Como antes se había masturbado pensando en niñas de entre 11 y 12 años (cosa que en un principio consideraba inaceptable moralmente), ¿quién le aseguraba que no acabaría pensando en niñas incluso de menor edad? o, peor aún, ¿cómo podía asegurarse de que no pasaría de la fantasía a la realidad? En relación con esta última preocupación, M. relató cómo, en una ocasión en la que se encontraba en la playa, observó a una niña pequeña (de unos cuatro años de edad) que correteaba completamente desnuda por la orilla. Enseguida, se dio la autoinstrucción: "Tengo que asegurarme de que no me atrae" y lanzó una fugaz mirada para comprobarlo, pero, entonces, M. pensó "He mirado a esa niña pequeña, soy un pervertido". 
A partir de ahí, el cliente no se preocupó por la posibilidad de que le surgieran fantasías con niñas de 11 o 12 años, sino por la posibilidad de que le aparecieran imágenes de aquella niña de cuatro años desnuda en la playa. Cuando se dijo a sí mismo: "No voy a pensar en esa niña pequeña", $M$. recuerda que en su mente apareció justamente la imagen de esa niña y, entonces, experimentó cierta relajación momentánea, seguida de un sentimiento de culpa por vivenciar esta relajación como placentera. A continuación se esforzó por alejar de su mente esas imágenes, pero cuanto más se esforzaba por no pensar en ella, más lo hacía y su tensión iba en aumento. Se sentía culpable por pensar en esa niña pequeña y sentía miedo ante la posibilidad de acabar masturbándose pensando en ella (como ya lo había hecho cuando le venían pensamientos relacionados con las niñas de 11 o 12 años).

M. se sentía fatal por tener esos pensamientos, pero al mismo tiempo pensaba que era su deber preocuparse por ellos y por eso no podía abandonarlos. Sabía por propia experiencia que no dejaría de preocuparse hasta que se rindiera a su obsesión y la integrara en una fantasía sexual mientras se masturbaba. Entonces pensó en hacer eso y sintió ambivalencia entre seguir reprimiéndose y controlando esos pensamientos o masturbarse para acabar con todo de una vez. Finalmente, tras muchos intentos de controlar sus pensamientos, y ante la imposibilidad de hacerlos desaparecer, $\mathrm{M}$. se rindió y también acabó masturbándose pensando en esa niña de cuatro años. Aunque, a corto plazo, M. experimentó una gran liberación de tensión, inmediatamente después se sintió terriblemente culpable, ya que el cliente pensaba que si masturbarse pensando en niñas de 11 o 12 años estaba mal, hacerlo con niñas de cuatro años era aún peor.

A partir de ahí, todos los esfuerzos de M. se centraron en evitar pasar de la fantasía a la realidad. Cuando se encontraba en alguna situación en la que surgía la posibilidad de llevar a cabo sus fantasías, como, por ejemplo, en una ocasión en la que la hija de sus vecinos, de cinco años de edad, se quedó a dormir en su casa, se preocupaba por la posibilidad de que esto ocurriera. La niña se había quedado al cuidado de la familia de M. porque sus padres habían salido a celebrar su aniversario de boda. En aquella situación el cliente pensaba: "Tengo que controlarme, no voy a pensar en abusar de ella", pero en su mente, justamente, lo que aparecía era "abusar de ella". Seguidamente, su cabeza era asaltada por múltiples pensamientos del tipo: "No soy capaz de hacerlo, pero si he pensando en ello es porque tal vez quiera hacerlo", "No quiero pensar más en esto, pero ¿cómo no voy a preocuparme por algo tan terrible?", "Si me preocupo es porque soy capaz de hacerlo", "Por otro lado, siento una gran curiosidad por tener una experiencia sexual de verdad", "Soy un pervertido por pensar así,", "Si lo hago no tiene por qué saberlo nadie", etc. Todos estos pensamientos hacían que M. experimentara sensaciones muy desagradables.

Aunque M. relata que consiguió controlar su impulso en aquella ocasión, la sensación que le quedó después fue de un gran malestar. Se sentía tan culpable como si hubiera abusado realmente de su vecina pequeña. Al cabo de unos cuantos meses, volvió a coincidir con esta niña en su casa, en la celebración de una barbacoa familiar. Entonces, se repitieron los mismos pensamientos y $\mathrm{M}$. experimentó las mismas sensaciones desagradables. El cliente sabía que, aunque consiguiera controlarse como la vez anterior, iba a seguir sintiéndose culpable, así que finalmente se rindió. No fue capaz de tocarla, pero se masturbó mientras la espiaba oculto tras el seto del jardín. Inmediatamente después, se sintió profundamente arrepentido y no se explicaba cómo pudo haber llegado a hacer algo así.

Además de masturbarse mientras espiaba a su vecina pequeña, también lo había hecho en un par de ocasiones mientras miraba en la playa a niñas pequeñas. A pesar de ello, el cliente asegura que estos episodios fueron aislados y que lo más frecuente era que se masturbara con fantasías y no espiando a niñas reales. Aunque M. informa que jamás tuvo contacto real con menores de edad y que no había 
mantenido otras conductas problemáticas, tales como buscar por Internet o descargar contenido pornográfico relacionado con menores, se sentía terriblemente angustiado por estos pensamientos y por la posibilidad de acabar pasando de la fantasía a la realidad.

\section{Análisis funcional y topográfico del caso}

Analizando toda la información que aporta el cliente M., parece claro que padece un trastorno de pedofilia, ya que cumple con los criterios diagnósticos que establece el $D S M-I V$-TR (APA, 2002).

Dicho esto, desde un enfoque basado en el análisis funcional, habría que dejar claro que este diagnóstico psicopatológico tiene una utilidad clínica limitada, ya que no ofrece ninguna clave a nivel funcional que pueda orientarnos a la hora de programar una intervención terapéutica. Para establecer el tratamiento adecuado se hace indispensable llevar a cabo el análisis funcional y topográfico de las conductas problemas con el objetivo de actuar sobre las variables relevantes de este caso en concreto.

Las conductas que el cliente M. señala como problemáticas son las fantasías sexuales recurrentes con niñas de corta edad y la preocupación por la posibilidad de pasar de la fantasía a la realidad. Desde el punto de vista topográfico, podemos considerar que las fantasías sexuales pedófilas que se dan cuando el cliente se dispone a masturbarse o cuando se encuentra próximo a niñas menores de edad (situación estimular desencadenante) van precedidas por las siguientes respuestas:

1. Respuesta cognitiva previa: el cliente tiene pensamientos del tipo "Seguro que vuelvo a caer" (miedo); "Tengo que evitar pensar en niñas pequeñas", "Tengo que controlarme" (evitación); "Estos pensamientos me producen placer, soy raro", "Soy un vicioso, no tengo fuerza de voluntad", "Soy un pervertido por pensar en estas cosas (culpa); "Sólo son fantasías, tampoco es tan grave", "No le voy a dar tanta importancia a esto" (ambivalencia).

2. Respuesta fisiológica previa: como consecuencia de la respuesta cognitiva señalada en el punto anterior, el cliente experimenta una activación fisiológica desagradable (agitación, ansiedad, etc.) y cierta activación presexual (inicio de los movimientos de erección del pene).

Como se puede apreciar, los pensamientos que generan miedo, evitación y culpa desencadenan una activación fisiológica que el cliente vivencia como desagradable. Además, a esta activación fisiológica desagradable se le une la activación sexual originada por las imágenes de contenido sexual (a pesar de ser catalogadas como inadecuadas e inmorales por el cliente). Esta activación aumenta aún más cuando aparecen pensamientos ambivalentes, ya que la persona se siente presionada a elegir entre dos opciones posibles (permitir la fantasía o no).

Además, los esfuerzos por evitar cierto contenido privado hacen que paradójicamente esté aún más presente en la mente del sujeto el contenido que pretende evitar (Hayes, Wilson, Gifford, Follete, \& Strosahl, 1996). Este fenómeno paradójico se ha puesto de manifiesto antes en varios trastornos tales como la drogodependencia (Marlatt, 1994); el trastorno obsesivo-compulsivo (Gold \& Wegner, 1995; McCarthy \& Foa, 1990); el trastorno de pánico (Craske, Street, \& Barlow, 1990); el trastorno de personalidad límite (Linehan, 1993; Stroshal, 1991); la depresión (Dougher \& Hackbert, 1994; Luciano \& Huertas, 1999); la bulimia (Nash \& Farmer, 1999); el alcoholismo (Velasco \& Quiroga, 2001; Wulfert, 1994); la ludopatía (Jiménez, 2013); y también en parafilias (LoPiccolo, 1994; Jiménez, 2012). Cuando cualquier persona que intenta evitar o suprimir un contenido, llamémosle X, necesariamente va a estar en relación o en contacto con dicho contenido $\mathrm{X}$, produciéndose un efecto paradójico. En nuestro caso, cuando M. se dice a sí mismo: "Tengo que evitar pensar en niñas pequeñas", ese enunciado ya contiene el contenido 
que se pretende evitar: niñas pequeñas. M. experimenta cierta relajación instantánea justo cuando aparece en su mente ese contenido evitado, puesto que si ya ha aparecido en su mente el contenido que le preocupaba que apareciese, se ahorra parte del esfuerzo necesario para seguirlo reprimiendo o suprimiendo.

Esta pequeña relajación instantánea, unida a la percepción de su propia activación presexual, hace que el cliente se sienta aún más culpable, ya que vivencia estos fenómenos como físicamente placenteros a pesar de que moralmente no sean aceptables. Además, estas percepciones lo encaminan a que anticipe el placer futuro que podrá experimentar si acepta esos pensamientos fantaseando con ellos voluntariamente. A continuación, el cliente realiza pequeños sondeos de comprobación, fantaseando brevemente con esas imágenes y comprobando que cuando aparecen lo hacen acompañadas de placer. Como los resultados de sus sondeos no son los deseados, el cliente se siente cada vez más confuso y culpable y, ante estas circunstancias, la activación fisiológica llega a hacerse tan insoportable que $\mathrm{M}$. se ve obligado a permitir y aceptar voluntariamente las fantasías pedófilas para que ésta disminuya.

Nuestro cliente experimentaba una gran tensión fisiológica cuando intentaba controlar sus pensamientos y todos los esfuerzos por evitar estas sensaciones eran infructuosos y hacían paradójicamente que se fuera sintiendo cada vez peor. Él ya sabía que si se masturbaba con estas fantasías, luego acabaría sintiéndose mal y culpable consigo mismo, pero la cuestión es que él ya estaba sintiéndose mal antes de hacerlo y además, debido a los efectos paradójicos de la evitación experiencial descritos, no había forma de suprimir tales pensamientos.

A nivel topográfico, las respuestas que emite M., al rendirse y masturbarse permitiendo las fantasías de carácter pedófilo, son las siguientes:

1. Respuesta cognitiva: el cliente, tras luchar sin éxito por controlar e intentar eliminar de su mente las fantasías relacionadas con menores, tiene el siguiente pensamiento: "No soporto la tensión, me rindo".

2. Respuesta motora: el cliente acaba masturbándose.

3. Respuesta fisiológica: descarga repentina y placentera de la activación fisiológica previa (agitación, ansiedad y tensión sexual acumulada).

Como se puede observar, la conducta del cliente sigue un patrón de reforzamiento negativo (el sujeto consigue eliminar el malestar fisiológico). Las consecuencias de las respuestas que emite son claras: a corto plazo M. ha descargado el malestar fisiológico desencadenado por los intentos de evitación/control de la conducta problema y la tensión sexual que se hubiera acumulado, pero a largo plazo se siguen desencadenando consecuencias negativas (aumento de la culpabilidad, asociación del placer con los estímulos pedófilos, deterioro de la autoestima del sujeto, etc.). Estas consecuencias negativas predispondrán al cliente a esforzarse más por controlar sus pensamientos y sensaciones la próxima vez que se encuentre ante la posibilidad de masturbase con fantasías pedófilas o de mantener un contacto pedófilo real.

\section{Tratamiento terapéutico del caso clínico basado en la terapia de aceptación y compromiso}

Teniendo en cuenta el análisis funcional y topográfico previo, la intervención terapéutica se dirigió a eliminar las conductas de control/evitación de pensamientos y sensaciones, dado que el propio intento de control/evitación constituye el factor principal del problema (Hayes et al., 1999; Wilson \& Luciano, 2002).

El primer paso consistió en desculpabilizar al cliente, ya que él se refería a sí mismo con etiquetas como "pedófilo", "pederasta" o "pervertido". Para ello, en las sesiones se evitó a toda costa emplear el término parafilia o similares $\mathrm{y}$, en su lugar, se empleaba el término problema, mucho menos 
estigmatizante. Además, se le hizo hincapié al cliente en el hecho de que él no debía considerarse ningún delincuente sexual puesto que jamás había mantenido contactos reales con menores y que los pensamientos, por desagradables o graves que parecieran, eran completamente inocuos. En referencia a tales pensamientos, se evitó catalogarlos como fantasías, ya que esta denominación implica cierto componente de deseo, de "querer llevarlo a cabo", y se hizo referencia a ellos como obsesiones, para que el cliente tuviera claro su carácter egodistónico.

Seguidamente, se hizo el repaso a la biografía expuesta por el paciente para que tomara consciencia de que el factor predisponente de su problema fue el hecho de, en el pasado, haber catalogado como inmoral algo que, por su edad, podía ser relativamente normal. Este hecho no es otro que el que hace referencia al episodio narrado en el que experimentó, a los 17 años, atracción por niñas de 11 o 12. Además, se le explicó cómo los pensamientos sexuales extravagantes (de toda índole) pueden ser frecuentes y darse puntualmente en cualquier persona y se le hizo hincapié en diferenciar el "yo como contexto" del "yo como contenido". Para conseguir esto, una metáfora que se empleó en esta fase del tratamiento fue la de "la casa y los muebles" (Wilson \& Luciano, 2002), según la cual la casa equivaldría al yo como contexto mientras que los muebles harían referencia al yo como contenido. Las cualidades que se atribuyan a los muebles (buenos, malos, agradables, desagradables, apropiados, inapropiados, etc.) no tienen por qué ser generalizadas a la casa. Por último, se le reforzó el hecho de que demandara ayuda, para que él mismo lo considerara una prueba de su integridad moral y del carácter egodistónico de sus pensamientos.

Otro aspecto que hacía sentir culpa al cliente era el hecho de que, aunque catalogaba sus pensamientos como inmorales y podía notar que le desagradaban o incomodaban, desde el punto de vista meramente físico le originaban sensaciones placenteras (erección, excitación y orgasmo). Para ayudar a M. a desprenderse de esa culpabilidad se le lanzó el mensaje "el pene no piensa" y se le explicó que cualquier contenido de índole sexual, por inmoral o extravagante que resultara, podía producir una activación momentánea de los genitales hasta que después se valore de forma racional si es adecuada o no. El cliente se dio cuenta de que, en su caso, su primera reacción fue la de desechar los contenidos que consideraba inapropiados, pero su mente insegura e hiperresponsable no se sintió satisfecha y siguió preocupándose por el tema, obligándolo a estar en contacto una y otra vez con los contenidos temidos.

Una vez que el cliente ya se había desprendido, al menos parcialmente, del exceso de culpabilidad que manifestaba, se procedió a la discusión junto al paciente de la finalidad y utilidad de las estrategias de control/evitación que venía utilizando hasta ahora, para que entendiera claramente que tales estrategias constituían el principal factor de mantenimiento de su problema. Uno de los motivos que dirigían a M. a intentar mantener bajo control los pensamientos e imágenes mentales relacionados con menores era, a parte del hecho de que los consideraba inmorales, el miedo a ser capaz de pasar de la fantasía a la realidad. A este respecto, se le explicó que, por mucho que pretendiera asegurarse, siempre existiría la posibilidad real de cometer los actos que temía. Absolutamente nadie, por muy equilibrado que fuera emocionalmente o por férreos que fueran sus principios morales, estaba libre de poder llevar a cabo conductas inapropiadas bajo determinadas circunstancias (trastorno mental transitorio, intoxicación aguda por drogas, etc.). Siempre existiría una posibilidad por remota que fuera, por mucho que intentara asegurarse, nunca podría estar seguro al cien por cien. Aunque este planteamiento produjo de inicio una gran ansiedad a M., al final se percató de lo ineficaces y contraproducentes que resultaban sus intentos de control.

Para ayudarle a entender mejor las explicaciones funcionales de su problema, se emplearon varias metáforas, elaboradas ad hoc, pero basadas parcialmente en las que aparecen en el manual de 
Wilson y Luciano (2002) y que, por cuestiones de espacio, se presentan sintetizadas:

1. Metáfora del monstruo: se le explicó al cliente que los pensamientos, imágenes y sensaciones temidas equivalen a un monstruo que crece y se pone más grande cuanta más atención se le presta. En cambio, si se ignora al monstruo, éste permanece pequeño e inofensivo.

2. Metáfora de los visitantes molestos: en esta metáfora, los pensamientos, imágenes y sensaciones temidas serían equivalentes a los visitantes molestos que acuden a una fiesta a la que no han sido invitados. Si el anfitrión les presta atención, éstos le impedirán disfrutar de su fiesta, $\mathrm{y}$, si intenta echarlos, puede producirse un conflicto desagradable que arruine definitivamente la reunión. La solución sería ignorarlos y centrarse en otros invitados a los que sí aprecia.

3. Metáfora de las alarmas: la activación fisiológica desagradable que se produce al contactar con el contenido mental temido equivaldría a múltiples alarmas que suenan estridentemente cuando hay algún peligro. Son útiles en cuanto nos avisan de la proximidad de un peligro (en este caso el masturbarse empleando un contenido mental inmoral), pero se vuelven insoportables si no se desactivan a tiempo. La cuestión es que están programadas para desactivarse por sí mismas y cualquier intento externo por apagarlas de otra manera hará que el sonido se vuelva más estridente aún.

El empleo de metáforas es una herramienta básica en la terapia de aceptación y compromiso (Hayes et al., 1999; Wilson \& Luciano, 2002), que permite a los sujetos tomar conciencia de forma clara de los fenómenos paradójicos de la evitación experiencial.

En esta fase de la intervención se produjo un estancamiento, ya que, a pesar de que el cliente entendía perfectamente que los intentos de represión de los pensamientos que temía hacían que aumentara su activación fisiológica, presentaba una gran resistencia a permanecer pasivo ante ellos, pues estaba convencido de que era "su deber" suprimirlos. Así, desde el punto de vista terapéutico, se tuvo que hacer bastante hincapié para que M. asimilara que la aceptación terapéutica de los pensamientos que se le proponía no implicaba estar de acuerdo con su contenido.

El cliente presentaba aún más dificultad para no prestar atención a tales pensamientos cuando éstos aparecían una vez que ya había iniciado la masturbación, ya que valoraba la aceptación terapéutica de los pensamientos o imágenes como generadora de excitación sexual o como productora de parte de su placer sexual. Así, M. no apreciaba ninguna diferencia cualitativa entre la aceptación terapéutica que se le proponía y la rendición que llevaba a cabo ante los pensamientos (lo que él entendía por fantasear) antes de haber iniciado el tratamiento psicológico. Para que el cliente asimilara las diferencias cualitativas entre ambos procesos (aceptación terapéutica frente a rendición compulsiva), se usó una nueva metáfora, elaborada ad hoc: la metáfora del conflicto bélico. Según ésta, cuando surge algún conflicto bélico, no es lo mismo que un determinado país se declare neutro (es decir, que no participe en la contienda) o que ese mismo país se rinda ante su enemigo o se alíe con él.

Finalmente, el cliente se comprometió con el hecho de aceptar que estos pensamientos seguirían apareciendo y que "las alarmas" seguirían sonando, pero eso no sería impedimento para llevar a cabo una vida plena según sus valores, orientada a conseguir metas. A este respecto, el propio cliente estableció como objetivos-valores, a corto-medio plazo, conseguir terminar la carrera de periodismo y establecer una relación de pareja con alguna chica de su edad. En relación con la consecución de este último objetivo, para terminar la intervención con M., se dedicaron varias sesiones al entrenamiento en habilidades sociales empleando la técnica del modelado y el role-playing. 
En total se llevaron a cabo 25 sesiones semanales, de las cuales dos fueron de evaluación y 23 de tratamiento. Al cabo de tres meses, se contactó telefónicamente con el cliente para llevar a cabo el seguimiento de su evolución terapéutica. M. comentó que, a pesar de que todavía tenía pensamientos e imágenes relacionadas con niñas menores de edad, éstos eran menos vívidos, no iban acompañados de una activación fisiológica tan desagradable como la que experimentaba en el pasado y, por lo general, eran reemplazados sin demasiadas dificultades por fantasías normalizadas (chicas de su edad), que le permitían masturbarse sin experimentar culpa. A los 10 meses se llevó a cabo un último contacto telefónico con $\mathrm{M}$. que sirvió para confirmar su evolución positiva, ya que, según comentó el cliente, los pensamientos relacionados con menores apenas aparecían y cuando lo hacían no lo alteraban demasiado, incluso aunque aparecieran durante la masturbación en las fases de máxima excitación. Aunque el cliente no había conseguido entablar ninguna relación afectiva o sexual con chicas de su edad, se mostraba bastante optimista a este respecto, asegurando que se sentía menos tímido a la hora de hablar con ellas y que había hecho algunas amigas entre sus compañeras de facultad.

\section{Conclusiones y discusión del caso}

Un estudio de caso único es obviamente insuficiente para llevar a cabo cualquier generalización de resultados, por lo que asumimos la necesidad de más validación empírica que respalde la eficacia de la ACT en el tratamiento de las parafilias sexuales. A pesar de ello, el desenlace satisfactorio del caso clínico expuesto nos permite albergar cierto optimismo al respecto de las posibilidades de dicha terapia, así como sugerir algunas consideraciones teóricas novedosas al respecto de la génesis y mantenimiento de las conductas parafílicas.

Así, el hecho de que este cliente solicitara ayuda debido a su pedofilia (todavía en fase germinal) contrasta con la idea generalizada de que los pedófilos suelen tener un perfil de personalidad antisocial y que no sienten culpa ni remordimientos, ya que rara vez acuden de manera voluntaria a solicitar terapia psicológica. Se asume que los pedófilos no quieren "curarse" de su parafília porque les resulta sumamente placentera. Quizás esto no sea tan sencillo. Posiblemente, los pedófilos sí experimentan culpa y remordimientos, es más, podría ser una hipótesis que esa culpa y remordimiento fueran los que hicieran que el problema se mantuviera y se agravara cada vez más (según lo visto en el análisis funcional de este caso). Quizás el contenido de las fantasías parafílicas, que se describe en el DSM$I V$-TR (APA, 2002) como altamente placentero para el cliente, sea tan egodistónico como las obsesiones de un TOC. Las fantasías sólo le resultan placenteras al sujeto si se rinde ante ellas a modo de compulsión (cognitiva o a través de una conducta real). Muy probablemente el motivo por el que los sujetos pedófilos no suelen pedir ayuda psicológica se deba a la consideración de que el hecho de sentir atracción sexual por niños pequeños no es un tema fácil de revelar a un profesional (debido al rechazo social que produce). En los pocos casos en los que se solicita terapia para actuar sobre estas inclinaciones sexuales, habría que estar sumamente atentos al posible efecto iatrogénico que puede tener la terapia sobre los sujetos, ya que pueden valorar el hecho de necesitar una intervención psicológica como la confirmación de que son "enfermos", "pervertidos" o "raros".

Otra implicación teórica que se puede sugerir con base en el caso expuesto sería el hecho de que probablemente no haya diferencias cualitativas, en el plano estrictamente sexual, entre las personas que padecen pedofilia (o cualquier otra parafilia) y el resto de la población. El propio Freud (1905) afirmaba en su obra Tres ensayos sobre la teoría sexual, refiriéndose a las perversiones (como se denominaban las parafilias en aquella época), lo siguiente: "la disposición a las perversiones es la disposición originaria y universal de la pulsión 
sexual de los seres humanos (...)". Así, la inteligencia humana permite a las personas descubrir muchas posibilidades sexuales y todas ellas tienen la capacidad de generar placer sexual, al menos desde el punto de vista fisiológico. Cualquier contenido mental de índole sexual, aunque pueda ser considerado, desde el punto de vista psicológico o moral, como desagradable por parte de los sujetos (egodistónicos), podría desencadenar una activación fisiológica a nivel sexual. Esta mínima activación sexual es instantáneamente inhibida, pero en las personas inseguras podría generar culpabilidad y conflictos morales que precipitarán los procesos evitativos descritos en el caso analizado. Luego, debido a los efectos paradójicos y contraproducentes de la evitación experiencial, es cuando los sujetos se verían obligados a rendirse ante los contenidos parafílicos para descargar la tensión acumulada por los esfuerzos evitativos. Por tanto, las diferencias entre los sujetos con parafilias y la población normal no radicarían en factores sexuales, sino que los factores clave serían los rasgos de personalidad insegura que predispondrían al patrón evitativo (Jiménez, 2012).

Durante la adolescencia, cuando se inicia el despertar hormonal, es normal que las personas ideen y busquen formas de experimentar placer sexual (en especial si todavía carecen de las habilidades sociales necesarias para iniciar contactos sexuales con otras personas). La mayoría baraja muchas posibilidades y descartan aquellas de las que luego puedan arrepentirse. A diferencia de los demás, que una vez rechazan la idea se olvidan de ella, algunos adolescentes más inseguros empiezan a atormentarse por haber barajado tales posibilidades, metiéndose de lleno en los círculos cerrados de evitación similares a los descritos en el caso clínico aquí presentado. En este punto sería interesante analizar el papel de protección que pueden desempeñar las bromas o el sentido del humor. A diferencia del cliente M., que se sentía terriblemente angustiado al percatarse de que las chicas de menos edad que él podían tener cierto atractivo físico, muchos jóvenes, que perciben el atractivo de chicas de menos edad que ellos, suelen descargar la tensión sexual o moral que les origina esta percepción bromeando directamente sobre los emergentes atributos sexuales de estas chicas en relación con su corta edad. La broma sería un "mecanismo de defensa" como los establecidos por Anna Freud (1936).

Dejando de lado ya las consideraciones teóricas y centrándonos exclusivamente en los aspectos terapéuticos del caso expuesto, hay que señalar algunas variables de éste que propiciaron su buen desenlace. Por ejemplo, es un factor relevante el hecho de que la parafilia se encontrara en fase germinal y que el cliente no hubiera llevado a cabo conductas pedófilas reales, ya que de lo contrario sería mucho más complicada una intervención satisfactoria. El cliente del caso expuesto aún conservaba su capacidad de excitación con estímulos sexuales normalizados, pero en los estadios avanzados de la pedofilia (o de cualquier otra parafilia) los sujetos suelen perder la capacidad de disfrutar con las relaciones sexuales normalizadas, ya que este tipo de interacciones no les va a permitir descargar tanta tensión como el contacto parafílico. Quizás, cuando estos individuos mantienen una relación sexual normalizada, lo hacen con la sensación de que es su obligación, de que deben intentar disfrutar con dichas relaciones y olvidarse de sus gustos parafílicos. Para ellos una relación sexual normalizada es una prueba o examen y poca gente realmente disfruta en los exámenes, por lo que la experiencia les resulta aversiva en comparación con las conductas parafílicas. Otro factor que ayudó a la buena resolución del caso fue el buen nivel intelectual del cliente, que le ayudó a asimilar sin problemas la explicación del análisis funcional de su conducta y las metáforas sobre los efectos de la evitación.

Para finalizar, se considera adecuado hacer mención a la importancia de la prevención desde la infancia de los patrones de personalidad insegura, ya que éstos se encuentran en la base del trastorno 
abordado en este artículo. Cuanto más inseguro sea un individuo, más importancia dará al hecho de tener bajo control sus pensamientos, imágenes mentales, emociones, etc., haciendo juicios constantes sobre la moralidad de éstos y poniéndose a prueba a sí mismo ante cualquier situación o estímulo que le resulte perturbador o amenazante para su integridad moral.

\section{Referencias}

American Psychiatric Association. (2002). DSM-IVTR. Manual diagnóstico y estadístico de los trastornos mentales. Barcelona: Masson.

Craske, M. G., Street, L., \& Barlow, D. H. (1990). Instructions to focus upon or distract from internal cues during exposure treatment of agoraphobic avoidance. Behaviour Research and Therapy, 27, 663-672.

Dougher, M. J. \& Hackbert, L. (1994). A behaviour-analytic account of depression and a case report using acceptance-based procedures. The Behaviour Analyst, 17, 321-334.

Freud, A. (1936). El Yo y los mecanismos de defensa. Barcelona: Ediciones Paidós.

Freud, S. (1905). Tres ensayos sobre teoría sexual. Barcelona: Ediciones Brontes.

Gold, D. B. \& Wegner, D. M. (1995). Origins of ruminative thought: Trauma, incompleteness, nondisclosure, and suppression. Journal of Applied Social Psychology, 25, 1245-1 261.

Hayes, S. C. (2004). Acceptance and commitment therapy, relational frame theory, and the third wave of behavioral and cognitive therapies. Behavior Therapy, 35, 639-665.

Hayes, S. C., Strosahl, K. D., \& Wilson, K. G. (1999). Accepttance and conmmitment therapy. An experiential approach to behavior change. Nueva York: Guilfor Press.

Hayes, S. C., Wilson, K. G., Gifford, E. V., Follete, V. M., \& Strosahl, K. (1996). Experiential avoidance and behavior disorder: a functional dimensional approach to diagnoses and treatment.
Journal of Consulting and Clinical Psychology, 64, $1152-1168$.

Jiménez, R. (2012). La génesis de las parafilias sexuales y la homosexualidad egodistónica: el modelo de los mecanismos tensionales. Avances en Psicología Latinoamericana, 30(1), 146-158.

Jiménez, R. (2013). Conceptualización y tratamiento terapéutico de un caso de ludopatía desde el análisis funcional y la terapia de aceptación y compromiso. Avances en Psicología Latinoamericana, 31(2), 443-452.

Linehan, M. M. (1993). Cognitive behavioral treatment of bordeline personality disorder. Nueva York: Guilford Press.

LoPiccolo, J. (1994). Acceptance and broad spectrum treatment of paraphilias. En S. C. Hayes, N. S. Jacobson, V. M. Follette, \& M. J. Dougher (Eds.), Acceptance and change: content and context in psychotherapy (pp. 149-170). Reno: Context Press.

Luciano, M. C. \& Huertas, F. (mayo, 1999). ACT through several cases. Association for Behavior Analysis. Chicago, IL.

Marlatt, G. A. (1994). Addiction and acceptance. En S. C. Hayes, N. S. Jacobson, V. M. Follette, \& M. J. Dougher (Eds.), Acceptance and change content and context in psychotherapy (pp. 175197). Reno: Context Press.

McCarthy, P. R. \& Foa, E. B. (1990). Obsessive-compulsive disorder. En M. E. Thease, B. A. Edelstein, \& M. Hersen (Eds.), Handbook of outponent treatment of adults: Noupsychotic mental disorders (pp. 209-234). Nueva York: Plenum.

Nash, H. M. \& Farmer, R. (1999). Modification of bulimia-related behavior in the context of acceptance and commitment therapy. Association for Behavior Analysis. Chicago, IL.

Stroshal, K. (1991). Cognitive and behavioral treatment of personality disordered patient. En C. Austad \& B. Berman (Eds.), Psychotherapy in managed health care: The optimal use of time and resources (pp. 185-201). Washington: APA. 
Velasco, J. A. \& Quiroga, E. (2001). Formulación y solución de un caso de abuso de alcohol en términos de aceptación y compromiso. Psicothema, 13(1), 50-56.

Wilson, K. G. \& Luciano, M. C. (2002). Terapia de aceptación y compromiso (ACT). Un tratamiento orientado a los valores. Madrid: Pirámide.
Wulfert, E. (1994). Acceptance in the treatment of alcoholism: a comparison of alcoholics anonymous and social learning theory. En S. Hayes, N. S. Jacobson, V. M. Follete, \& M. J. Dougher (Eds.), Acceptance and change: Content and context in psychotherapy (pp. 203-217). Reno, Nevada: Context Press. 
